\section{Design of a Patient Wrist Rehabilitation Device with Servo Motor Drive}

\author{
Lukman Yassir Amali, I Made Londen Batan* \\ Department of Mechanical Engineering, Institut Teknologi Sepuluh Nopember, Surabaya 60111, Indonesia \\ Received: 27 February 2020, Revised: 10 September 2020, Accepted: 13 September 2020
}

\begin{abstract}
Stroke represents a condition that occurs when the blood supply to the brain is interrupted or reduced due to a blockage (ischemic stroke) or rupture of a blood vessel (hemorrhagic stroke). A person who suffers a stroke will have a brain disorder that causes him/her unable to carry out activities like other healthy people. In general, stroke sufferers have paralysis in several parts of the body, like the hands, feet, and even the face. With technological developments in this era, stroke can be healed in various ways that have been developed by health experts. Healing can be referred to the treatment result for blocked or damaged blood vessels. However, the sufferer's paralysis cannot return to the normal condition immediately, so it requires therapy or exercises to stimulate the muscles in the hands, feet, or face. This study focuses on developing a therapeutic device on the wrist that has a swivel joint. To design the wrist rehabilitation device with servo motor drive, some researches about existing products need to be reviewed. From that, a list of requirements is compiled, which is used for designing the concept of a wrist rehabilitation device. It is expected that an automatic wrist rehabilitation device can help post-stroke patients undergo the rehabilitation process.
\end{abstract}

Keywords: Stroke, rehabilitation, wrist, therapeutic device, servo motor

\section{Introduction}

Stroke is a condition that occurs when the blood supply to the brain is interrupted or reduced due to a blockage (ischemic stroke) or rupture of a blood vessel (hemorrhagic stroke). Without blood, the brain will not get oxygen and nutrients, so cells in several areas of the brain will die.

Most stroke survivors have paralysis in their limbs. Some were completely paralyzed, some were paralyzed by half. Patients who are declared cured of a stroke are still considered abnormal. Because it still needs rehabilitation to recover limbs that are paralyzed. In this study, the focus was on the rehabilitation of the arm-hand in post-stroke patients.

Rehabilitation efforts are carried out after poststroke patients undergo a recovery process which is usually carried out with physiotherapy. Physiotherapy is the process of rehabilitating a person to avoid physical disability through a series of prevention, diagnosis, and treatment to prevent physical disorders in the body due to injury or disease. Physiotherapists are performed on patients of all ages and body conditions, for example, to treat back pain, neck pain, wrist pain, and preparation for labor.

To specifically prevent nervous tension in the hands, there are several rehabilitation tools, namely aeboflex and pictor. Saeboflex is designed for handgrip rehabilitation and grip strength. Meanwhile, the Pictor rehabilitation tool is designed to focus more on wrist rehabilitation. Both of these tools can be used for wrist rehabilitation of post-stroke patients. However, its use is still manual, so a therapist is needed to assist in wrist therapy.

To be able to carry out the therapy on your own, this research will develop a wrist rehabilitation device that is driven by a servo motor. The development of a wrist rehabilitation device that is comfortable, safe, strong, and inexpensive can also be controlled by the patient.

\section{Study Literature}

\subsection{Body Weight Segment}

Kroemer-Elbert ergonomist [1], dividing the weight of human body parts based on empirical activity in the laboratory. It is stated that the human body is divided into several segments, including head, neck, torso, hands, and feet [1]. The weight of each segment is calculated based on the total body weight (W), as can be seen in Table 1 .

\subsection{RULA analysis}

Rapid Upper Limb Assessment (RULA) is a method for assessing a person's posture and muscles while doing an activity [2]. RULA measures the degree of risk of injury from the activities carried out. The application of the RULA method requires 3 (three) steps to assess body posture, namely: 1) the location of the body work posture,

"Corresponding author. Email : londbatan@me.its.ac.id 
Table 1. Equation for Estimating Body Segment Mass (Kg) Based on Total Body Weight

\begin{tabular}{cc}
\hline Segment & Empirical Equations \\
\hline Head & $0.0306 \mathrm{~W}+2.46$ \\
Head and Neck & $0.0534 \mathrm{~W}+2.33$ \\
Neck & $0.0146 \mathrm{~W}+0.60$ \\
Head, Neck and Torso & $0.5940 \mathrm{~W}-2.20$ \\
Neck and Torso & $0.5582 \mathrm{~W}-4.26$ \\
Total Arm & $0.0505 \mathrm{~W}+0.01$ \\
Upper ar & $0.0274 \mathrm{~W}-0.01$ \\
Forearms and Head & $0.0233 \mathrm{~W}-0.01$ \\
Forearm & $0.0189 \mathrm{~W}-0.16$ \\
Hand & $0.0055 \mathrm{~W}+0.07$ \\
Total Feet & $0.1582 \mathrm{~W}+0.05$ \\
Thigh & $0.1159 \mathrm{~W}-1.02$ \\
Calves and Feet & $0.0452 \mathrm{~W}+0.82$ \\
Calf & $0.0375 \mathrm{~W}+0.38$ \\
Feet & $0.0069 \mathrm{~W}+0.47$ \\
\hline
\end{tabular}

GROUP A. Arm and Wrist Analysis

Step 1 : Locate Upper Arm Position :

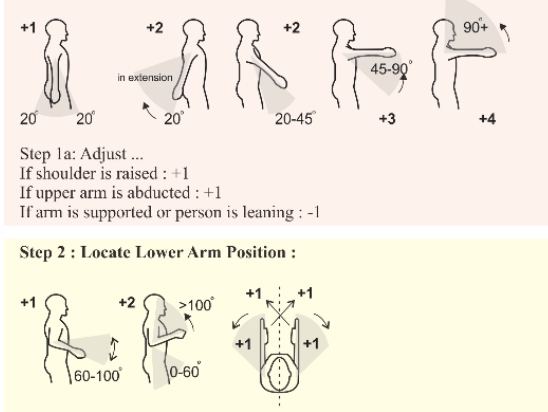

Step 2a: Adjust ...
If either arm is working across midline or out to side of body: Add +1

Step 3 : Locate Wrist Position:

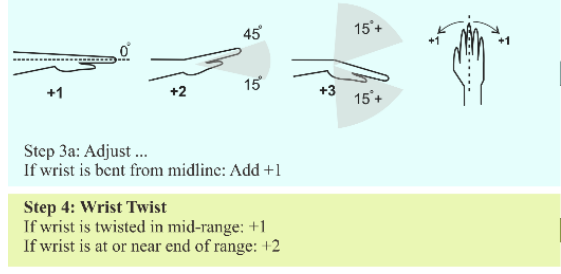

GROUP B. Neck, Back, and Leg Analysis

Step 9 : Locate Neck Position :

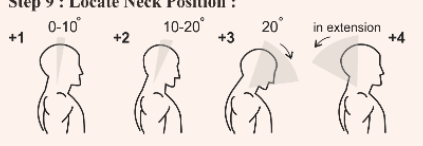

Step 9a: Adjust ...

If neck is twisted : +1
If neck is side bending : +

Step 10 : Locate Back Position :
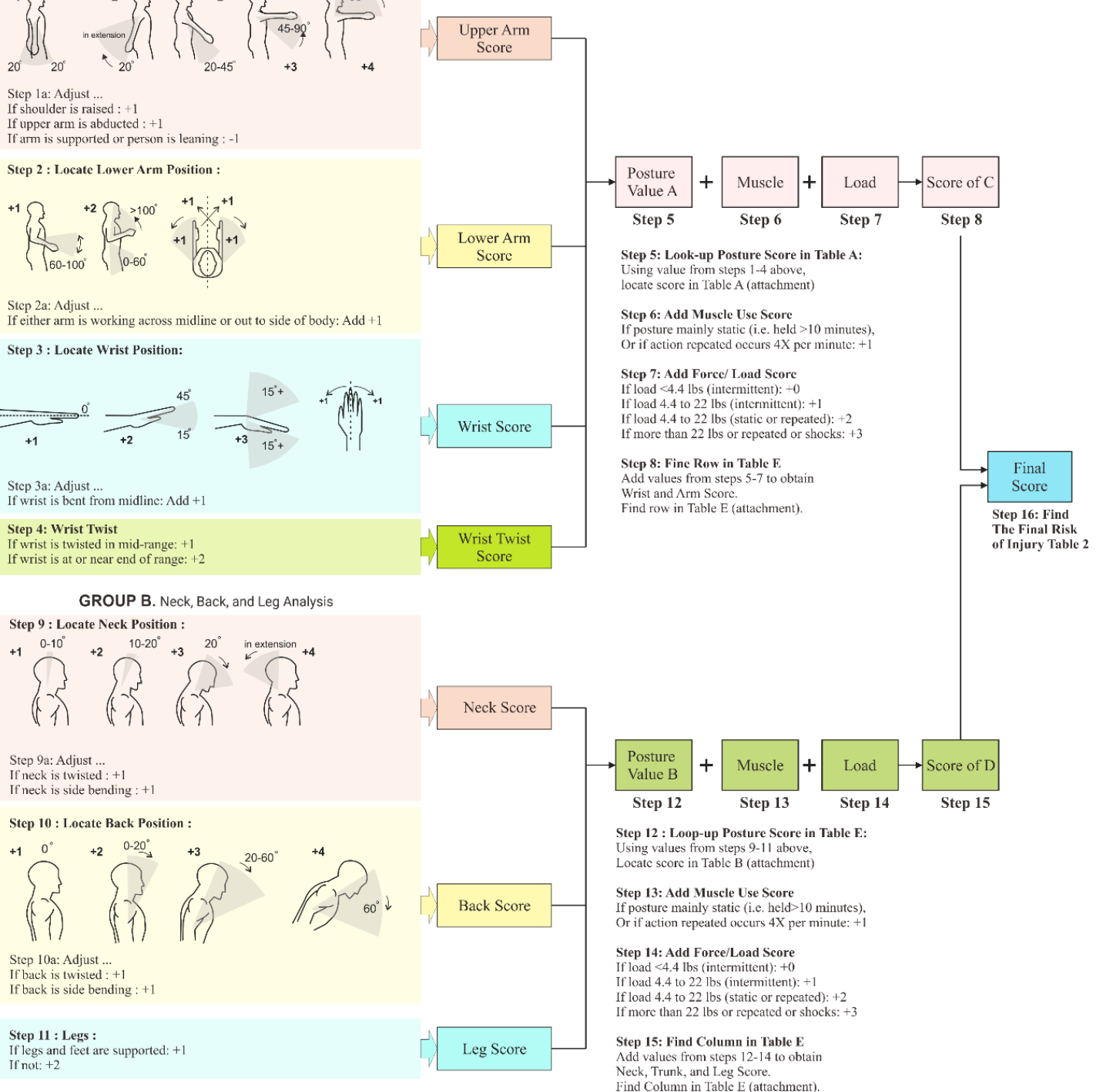

Figure 1. Determination of RULA 


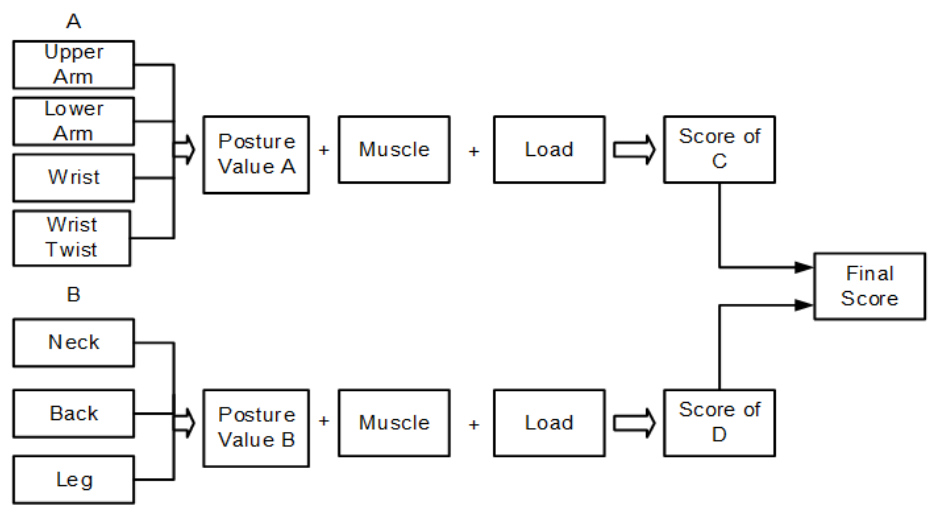

Figure 2. Sum of the values of posture (group) A and posture (group) B as well as muscle values and body weight each posture [3]

2) the assessment of the body work posture group, and 3) the sum of the total score [4].

Figure 1 show the position of each limb with the risk of injury during the activity, where the value that emerges from the position of the body post plus the value resulting from the specific condition of the work posture. This shows that the whole-body posture will pose a risk of injury due to the position of the body posture in a certain position when a person is. In addition, in the risk assessment, the consequences of a foreign load on the glands and back that are continuous or intermittent are also included [5]. The sum of the total physical values of the body can be seen in Figure 2. To make it easier to assess the physical value of the body of water, the application of the RULA method is simulated with CATIA software.
In accordance with the description of the steps in the RULA method above, the scores for the injuries in each body posture (groups A and B) are grouped, then the total value of the two groups (postures) of the body with the weight and external load of each posture is grouped, then the total value two groups (postures) of the body with the weight and load outside each posture are grouped, with the indicated by a score of $C$ and score of $D$. To determine the posture value of groups A, may use the table A, as shown in Table 2. And also, to determine the posture value of groups B, may use the table B, as shown in Table 3. With table E, shown in Table 4, the total value of the two groups (posture) of the body can be determined and becomes a risk of injury person value, as shown in Figure 3 .

Table 2. Wrist posture score table (Table A)

\begin{tabular}{|c|c|c|c|c|c|c|c|c|c|}
\hline \multicolumn{10}{|c|}{ Wrist Twist Score } \\
\hline \multirow{3}{*}{$\begin{array}{l}\text { Upper } \\
\text { Arm }\end{array}$} & \multirow{3}{*}{$\begin{array}{l}\text { Lower } \\
\text { Arm }\end{array}$} & & & \multirow{2}{*}{\multicolumn{2}{|c|}{$\frac{2}{\text { Wrist twist }}$}} & \multirow{2}{*}{\multicolumn{2}{|c|}{$\frac{3}{\text { Wrist twist }}$}} & & \\
\hline & & \multicolumn{2}{|c|}{$\frac{1}{\text { Wrist twist }}$} & & & & & \multicolumn{2}{|c|}{ Wrist twist } \\
\hline & & 1 & 2 & 1 & 2 & 1 & 2 & 1 & 2 \\
\hline \multirow{3}{*}{1} & 1 & 1 & 2 & 2 & 2 & 2 & 3 & 3 & 3 \\
\hline & 2 & 2 & 2 & 2 & 2 & 3 & 3 & 3 & 3 \\
\hline & 3 & 2 & 3 & 3 & 3 & 3 & 3 & 4 & 4 \\
\hline \multirow{3}{*}{2} & 1 & 2 & 3 & 3 & 3 & 3 & 4 & 4 & 4 \\
\hline & 2 & 3 & 3 & 3 & 3 & 3 & 4 & 4 & 4 \\
\hline & 3 & 3 & 4 & 4 & 4 & 4 & 4 & 5 & 5 \\
\hline \multirow{3}{*}{3} & 1 & 3 & 3 & 4 & 4 & 4 & 4 & 5 & 5 \\
\hline & 2 & 3 & 4 & 4 & 4 & 4 & 4 & 5 & 5 \\
\hline & 3 & 4 & 4 & 4 & 4 & 4 & 5 & 5 & 5 \\
\hline \multirow{3}{*}{4} & 1 & 4 & 4 & 4 & 4 & 4 & 5 & 5 & 5 \\
\hline & 2 & 4 & 4 & 4 & 4 & 4 & 5 & 5 & 5 \\
\hline & 3 & 4 & 4 & 4 & 5 & 5 & 5 & 6 & 6 \\
\hline \multirow{3}{*}{5} & 1 & 5 & 5 & 5 & 5 & 5 & 6 & 6 & 7 \\
\hline & 2 & 5 & 6 & 6 & 6 & 6 & 7 & 7 & 7 \\
\hline & 3 & 6 & 6 & 6 & 7 & 7 & 7 & 7 & 8 \\
\hline \multirow{3}{*}{6} & 1 & 7 & 7 & 7 & 7 & 7 & 8 & 8 & 9 \\
\hline & 2 & 8 & 8 & 8 & 8 & 8 & 9 & 9 & 9 \\
\hline & 3 & 9 & 9 & 9 & 9 & 9 & 9 & 9 & 9 \\
\hline
\end{tabular}


Table 3. Trunk posture score table (Table B)

\begin{tabular}{|c|cc|cc|cc|cc|cc|cc|}
\hline \multicolumn{10}{|c|}{ Back Score } \\
\hline \multirow{3}{*}{ Neck Score } & 1 & \multicolumn{2}{c|}{2} & \multicolumn{1}{c|}{3} & \multicolumn{1}{c|}{4} & \multicolumn{2}{c|}{5} & \multicolumn{2}{c|}{6} \\
\cline { 2 - 15 } & Leg & \multicolumn{2}{c|}{ Leg } & \multicolumn{2}{c|}{ Leg } & \multicolumn{2}{c|}{ Leg } & \multicolumn{2}{c|}{ Leg } & \multicolumn{2}{c|}{ Leg } \\
\cline { 2 - 14 } & 1 & 2 & 1 & 2 & 1 & 2 & 1 & 2 & 1 & 2 & 1 & 2 \\
\hline 1 & 1 & 3 & 2 & 3 & 3 & 4 & 5 & 5 & 6 & 6 & 7 & 7 \\
\hline 2 & 2 & 3 & 2 & 3 & 4 & 5 & 5 & 5 & 6 & 7 & 7 & 7 \\
\hline 3 & 3 & 3 & 3 & 4 & 4 & 5 & 5 & 6 & 6 & 7 & 7 & 7 \\
\hline 4 & 5 & 5 & 5 & 6 & 6 & 7 & 7 & 7 & 7 & 7 & 8 & 8 \\
\hline 5 & 7 & 7 & 7 & 7 & 7 & 8 & 8 & 8 & 8 & 8 & 8 & 8 \\
\hline 6 & 8 & 8 & 8 & 8 & 8 & 8 & 9 & 9 & 9 & 9 & 9 & 9 \\
\hline
\end{tabular}

Table 4. Final score table (Table E)

\begin{tabular}{|c|c|c|c|c|c|c|c|c|}
\hline & \multicolumn{7}{|c|}{ Score D (neck, back, leg) } \\
\hline & & 1 & 2 & 3 & 4 & 5 & 6 & 7 \\
\hline \multirow{7}{*}{ Score C (upper limb) } & 1 & 1 & 2 & 3 & 3 & 4 & 5 & 5 \\
\hline & 2 & 2 & 2 & 3 & 4 & 4 & 5 & 5 \\
\hline & 3 & 3 & 3 & 3 & 4 & 4 & 5 & 6 \\
\hline & 4 & 3 & 3 & 3 & 4 & 5 & 6 & 6 \\
\hline & 5 & 4 & 4 & 4 & 5 & 5 & 7 & 7 \\
\hline & 6 & 4 & 4 & 5 & 6 & 6 & 7 & 7 \\
\hline & 7 & 5 & 5 & 6 & 7 & 7 & 7 & 7 \\
\hline
\end{tabular}

The final risk of injury with the RULA method has a range of 1 to 7 which is described in Table 5 .

\subsection{Failure Theory}

Failure is defined as the inability of an element / component to achieve its function when given a certain load. Machine element failures can occur in the form of cracks, fractures, corrosion, wear and other failure conditions [6]:

$$
\tau_{\max } \leq \frac{\tau_{y s}}{N}
$$

Information:

$$
\tau_{\max }=\text { Maximum design shear stress }
$$

$$
\begin{array}{ll}
\tau_{y s} & =\text { Design yield shear stress } \\
N & =\text { Safety factor }
\end{array}
$$

Table 5. Assessing the level of risk of injury

\begin{tabular}{cl}
\hline Score & Description \\
\hline 1 and 2 & : Accepted \\
3 and 4 & $:$ It needs investigation and changes to the type of movement or needs to improve the design \\
5 and 6 & $:$ Immediately conducted an investigation \\
7 & : Investigations and changes must be made \\
\hline
\end{tabular}




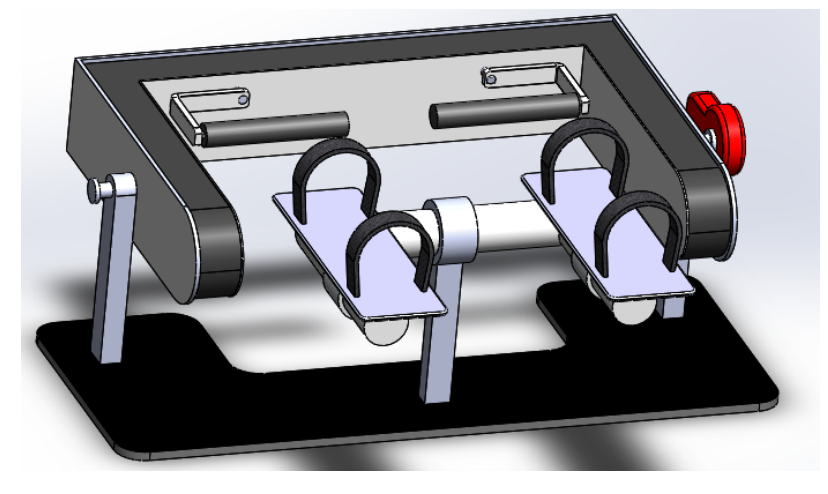

Figure 3. Hand wrist rehabilitation equipment

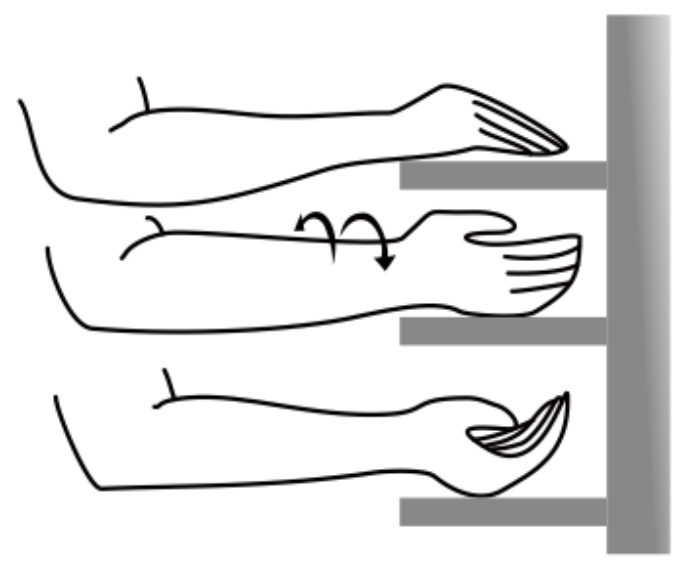

Figure 4. Supination and Pronation Movement

Information :

$\sigma_{t} \quad=$ Maximum tensile stress of design

$\sigma_{c} \quad=$ The maximum compressive stress of the design

$S_{y t} \quad=$ Design yield tensile stress

$S_{y c} \quad=$ Compressive stress design yield

$N \quad=$ Safety factor

$S_{\max }=$ Maximum Voltage

$S_{\text {syp }} \quad=$ Permit Voltage for Material

$S_{y p} \quad=$ Yield Strength Material

\subsection{Study of Existing Products}

Wrist Rehabilitation Imaging Devices are wrist rehabilitation devices that exist for post-stroke patients and have been sold in large quantities. Pictor allows the user to achieve maximum wrist rehabilitation based on the active and independent exercises needed to rebuild the anatomical function of the hand. This product has a length of $360 \mathrm{~mm}$, a width of $620 \mathrm{~mm}$, a height of $240 \mathrm{~mm}$, and a weight of $17 \mathrm{~kg}$. There is a special table for the use of this product that can help assemble the Pictor's rehabilitation tool, easy to use anywhere and neat. This particular table has dimensions of $945 \mathrm{~mm}$ long, $450 \mathrm{~mm}$ wide, and 720 mm high.

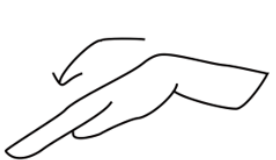

Flexion

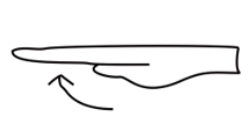

Extension

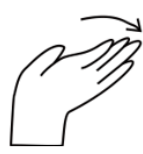

Abduction

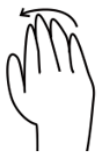

Adduction
Figure 5. Flexion extension motion and adduction abduction

How to use the Wrist Rehabilitation Tool is as follows: The patient's hand is inserted through two loose (black color) belts, then the hand holds the stem (red color). Then tighten the belt at the arm so that the hands are not tightly tied to the belt. There are two locks on the rehabilitation device, namely the front and sidelocks. Each of them has an important function. If the side lock is closed and the front lock is loosened, the patient's hand will move supination and pronation. Supination and pronation movements can be seen in Figure 4.

When the front lock is closed and the side locks are loosened, the patient's hand can perform flexion and extension movements while the hand is in the pronation position. And the patient's hand performs abduction and adduction movements while the patient's hand is in an upright position. The motion of extension flexion and adduction abduction can be shown in Figure 5 .

Mechanically, the Hand wrist strap rehabilitation tool has fulfilled its function, namely as a wrist rehabilitation tool for post-stroke patients or even a wrist strap that has started to stiffen due to the same activity over and over again. With a front and side locking mechanism, it can also perform a combination of movements. However, to develop it, it is necessary to conduct a study, namely by evaluating this product. The results showed several things, including:

1. Patients undergoing rehabilitation with this product must be accompanied by a therapist. The reason is, the hand wrist rehabilitation tool is designed for post-stroke patients who can already move their hands even though they are still not smooth. This makes the process and implementation of wrist rehabilitation in post-stroke patients more expensive.

2. Not all stroke sufferers experience total paralysis. Many stroke patients also experience partial paralysis in their bodies. As in Figure 3, the hand wrist rehabilitation equipment provides wrist therapy for both the patient's hands. Therefore, it can be said that it is less efficient if this tool is used by patients who have partial body paralysis.

3. In Figure 3, you can see that this product is placed on a special table that supports the hand wrist rehabilitation unit. This makes rehabilitation equipment not easy to use anywhere. In other word, it could be said, this product is less flexible. 


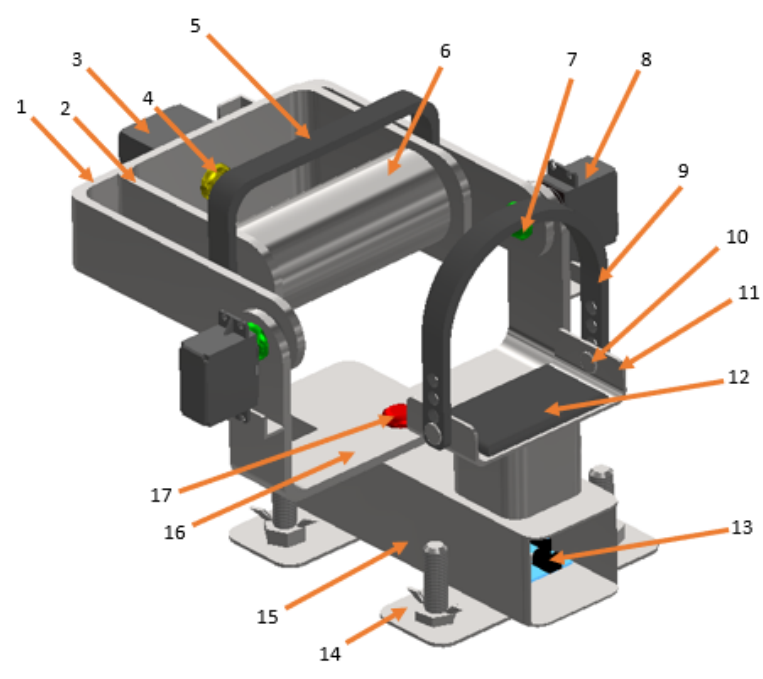

Figure 6. Components of a new wrist rehabilitation device

4. The hand wrist rehabilitation equipment has a weight of $17 \mathrm{~kg}$ and large dimensions with a length of $360 \mathrm{~mm}$, a width of $620 \mathrm{~mm}$ and a height of $240 \mathrm{~mm}$. This makes the hand wrist rehabilitation equipment need a large area for rehabilitation.

5. The price offered from the manufacturer for this product is around 18.5 million rupiah, this tool is quite expensive.

\subsection{Design of Wrist Rehabilitation Device}

After conducting an assessment of the working principles of the existing wrist rehabilitation equipment, a new concept will be created to correct deficiencies of the previous product. Of course, the concept that will be created is based on a list of requirements that have been compiled.

The wrist rehabilitation design has a total length of $350,459 \mathrm{~mm}$, a total width of $216 \mathrm{~mm}$, and a total height of $167,632 \mathrm{~mm}$. The main components of the barrier rehabilitation device can be seen in Figure 6 and Table 6.

The way the Wrist Rehabilitation equipment works is not the same as the hand wrist rehabilitation device works. One of the spacers is placed on the Arm Plate, then holds the Handle. Then the adhesive belt is glued, while the adhesive belt does not lock too quickly. This is intended to avoid injury to the patient's arm. An adhesive arm belt should be used to prevent the patient's hand from moving in any direction which could cause the patient's arm to fall from the rehab tool and could be fatal. After that the Arduino is turned on and the servo motor will automatically rotate and can still be controlled according to the training program that has been prepared.

\section{Results and Discussion}

\subsection{RULA analysis}

There are 2 hand grip positions analyzed, namely the debt position under the grip (pronation) and above the grip (supination). The second position is done by doing a RULA Simulation, which is by drawing a dwarf as the embodiment of a person and the position of the hand when holding the grip. RULA simulations were carried out with the help of CATIA V5 R20 software. In both cases, the injury to injury is the same, namely 3 . This means that the concept of wrist strap rehabilitation is still safe to use in the lower (pronated) and upper (supination) hand positions.

Table 6. The main components of equipment (refer to Figure 6)

\begin{tabular}{clc}
\hline No. & \multicolumn{1}{c}{ Component Name } & Amount \\
\hline 1. & Plate for abduction and adduction movements (Hand Plate-B) & 1 \\
2. & Plate for pronation and supination movements (Hand Plate-C) & 1 \\
3. & Servo Motor C (SG90) & 1 \\
4. & Pronation and supination movement pins & 1 \\
5. & Hand adhesive belt & 1 \\
6. & Handgrip & 1 \\
7. & Abduction and adduction motion pins & 2 \\
8. & Servo Motor B (1501 MG) & 2 \\
9. & Sleeve adhesive belt & 1 \\
10. & Sleeve adhesive pin & 2 \\
11. & Plate for laying the arm (Forearm Plate) & 1 \\
12. & Arm bearing & 1 \\
13. & Arduino UNO R3 & 1 \\
14. & Bracket for fastening to the table & 2 \\
15. & Box for Arduino & 1 \\
16. & Plate for flexion and extension movements (Hand Plate-A) & 1 \\
17. & Flexion and extension motion pins & 1 \\
\hline
\end{tabular}




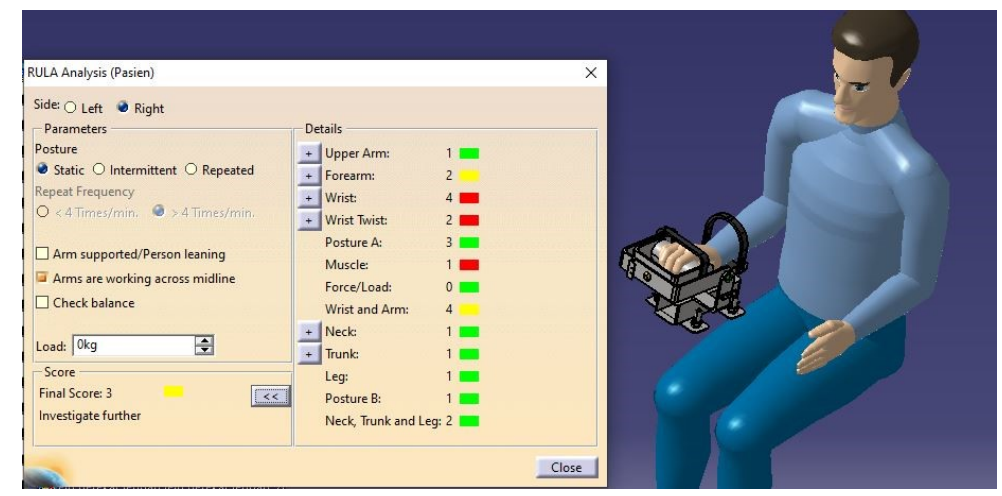

Figure 7. Results of RULA analysis on the position of the hands looking down (pronation)

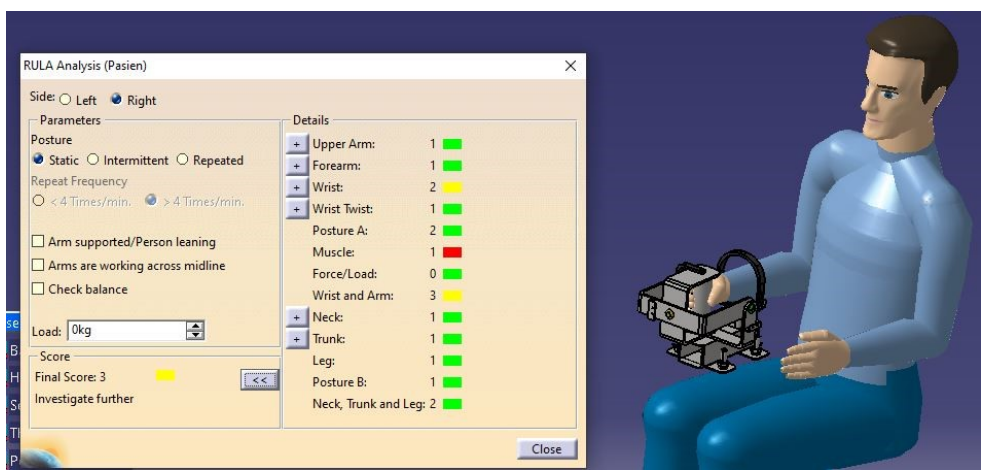

Figure 8. RULA analysis results on the hand holding the grip facing upwards (supination) and the position of the arm upright

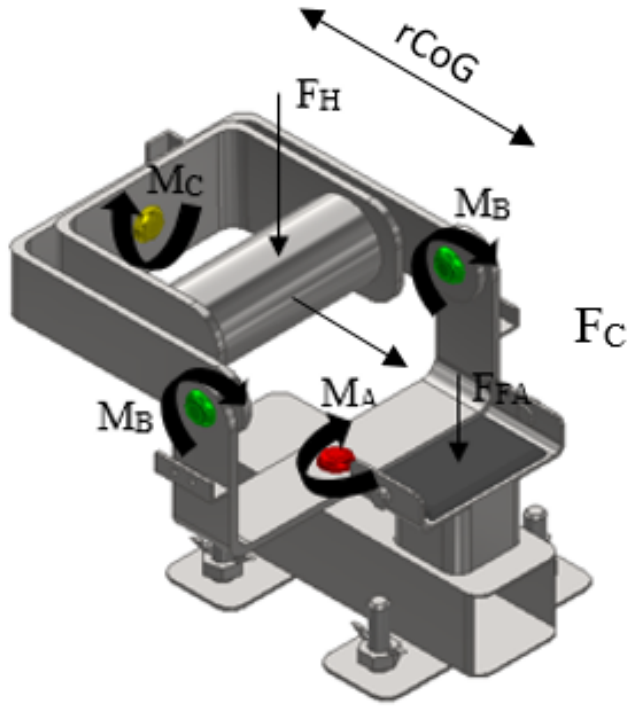

Figure 9. Diagram of Hand-Free Hand Rehabilitation Device

\subsection{Calculation of Force on Main Components}

To analyze the strength of the material used, the main components of the wrist rehabilitation tool are calculated. Figure 9 shows the Free Body Diagram of the wrist rehabilitation tool body skeleton.

The forces that occur on the wrist strap rehabilitation device include $\mathrm{FH}$, namely the hand holding the handgrip, then FFA which is the arm load, then the MA moment is the moment that works on pin A, MB is moment works on pin $\mathrm{B}$, and $\mathrm{MC}$ is moment works on pin $\mathrm{C}$. In order the calculate the magnitude of the work force of FH and FFA, the equation in Table 1 can be used, namely:

$$
\begin{aligned}
\text { Mass }_{\text {hand }} & =0.0055 \mathrm{~W}+0.07 \\
& =0.0055(100 \mathrm{Kg})+0.07 \\
& =0.62 \mathrm{Kg} \\
& =\text { Mass }_{\text {hand }} \times \text { gravity } \\
& =0.62 \mathrm{Kg} \times 9.81 \mathrm{~m} / \mathrm{s}^{2} \\
& =6.1 \mathrm{~N} \\
\text { Mass }_{\text {arm }} & =0.0189 \mathrm{~W}-0.16 \\
& =0.0189(100 \mathrm{Kg})-0.16 \\
& =1.73 \mathrm{Kg} \\
& =\text { mass }_{\text {hand }} \times \text { gravity } \\
& =1.73 \mathrm{Kg} \times 9.81 \mathrm{~m} / \mathrm{s}^{2} \\
& =17 \mathrm{~N}
\end{aligned}
$$

The moment that acts on pins $\mathrm{A}, \mathrm{B}$, and $\mathrm{C}$, can be calculated using the following equation:

$$
\mathrm{M}_{A} \quad=\frac{1}{2} \mathrm{~F}_{C} \times \frac{1}{2} \mathrm{r}
$$

$\mathrm{F}_{C}$ is the handgrip force in post-stroke patients, which is assumed to be the magnitude for the post-stroke patient's 
average handgrip strength is $10 \mathrm{~kg}$ or equal to $98 \mathrm{~N}$. That value is the average value during the gripping style of stroke patients before exercising [7], while $r$ is the length of the arm from plate $\mathrm{A}(\mathrm{r}=90 \mathrm{~mm})$, so that:

$$
\begin{aligned}
\mathrm{M}_{A} & =49 \times 45 \\
& =2.205 \mathrm{Nmm}
\end{aligned}
$$

By using the next equation, the moment on pin $\mathrm{B}=\mathrm{MB}$ will be determined as follow:

$$
\mathrm{M}_{B}=\mathrm{F}_{T O T} \times \mathrm{r}_{C o G}
$$

For the $\mathrm{F}_{T O T}$ it is obtained from the sum of yield, weight of plate- $B$, weight of plate- $C$, and weight of servo $C$, while $\mathrm{r}_{C o G}$ is the length of arm form plate $\mathrm{B}\left(\mathrm{r}_{C o G}=72.706\right.$ $\mathrm{mm}$ ), so that:

$$
\mathrm{M}_{B} \quad=42 \mathrm{~N} \times 72.706 \mathrm{~mm}
$$

Since the force acts on 2 points, namely point B1 and B2, the moment value is divided into 2 , so that:

$$
\begin{aligned}
\mathrm{MB1} & =\mathrm{MB} 2=\mathrm{MB} \\
& =3,053.65 \mathrm{Nmm}
\end{aligned}
$$

The moment in pin C (MC) will be calculated and depend on the value of hand holding the handgrip $\mathrm{FH}$ and the length of the handgrip. If $\mathrm{FH}$ is $6.1 \mathrm{~N}$, while $\mathrm{L}=120 \mathrm{~mm}$, so that the value of MC is as follow:

$$
\begin{aligned}
\mathrm{MC} & =\frac{1}{2} \mathrm{~F}_{H} \times \frac{1}{4} \mathrm{~L} \\
& =3.05 \times 30 \\
& =91.5 \mathrm{Nmm}
\end{aligned}
$$

\subsection{Servo Motor Selection}

In accordance with the force and moment calculations that have been done above, the torque required to run each plate on the wrist rehabilitation tool is 2,205 $\mathrm{Nmm}, 3,053.65 \mathrm{Nmm}$, and $91.5 \mathrm{Nmm}$. So to meet the torque requirements, the appropriate servo motors are planned, namely servo motors of the SG90, 1501 MG, and DS3225 types. The SG90 servo has a stall torque of $1.8 \mathrm{kgF} \mathrm{cm}$ or equivalent to $176.52 \mathrm{Nmm}$ when given a voltage input of 4.8 volts and $2.5 \mathrm{kgF} \mathrm{cm}$ or equivalent to $245.17 \mathrm{Nmm}$ if given a voltage input of 6 volts. Servo $1501 \mathrm{MG}$ has a stall torque of $15.5 \mathrm{kgF} \mathrm{cm}$ or equivalent to $1520 \mathrm{Nmm}$ when given an input voltage of 4.8 volts and $17 \mathrm{kgF} \mathrm{cm}$ or equivalent to $1667.13 \mathrm{Nmm}$ if given an input voltage of 6 volts. Meanwhile, the DS3225 servo has a stall torque of $21 \mathrm{kgF} \mathrm{cm}$ or equivalent to $2,059.4$ $\mathrm{Nmm}$ if given an input voltage of 5 volts and $25 \mathrm{kgF} \mathrm{cm}$ or the equivalent of $2,451.66 \mathrm{Nmm}$ if given an input voltage of 6.8 volts. With these specifications, the SG90.1501 MG and DS3225 servo motors are considered capable of driving the plates in the design of this equipment.

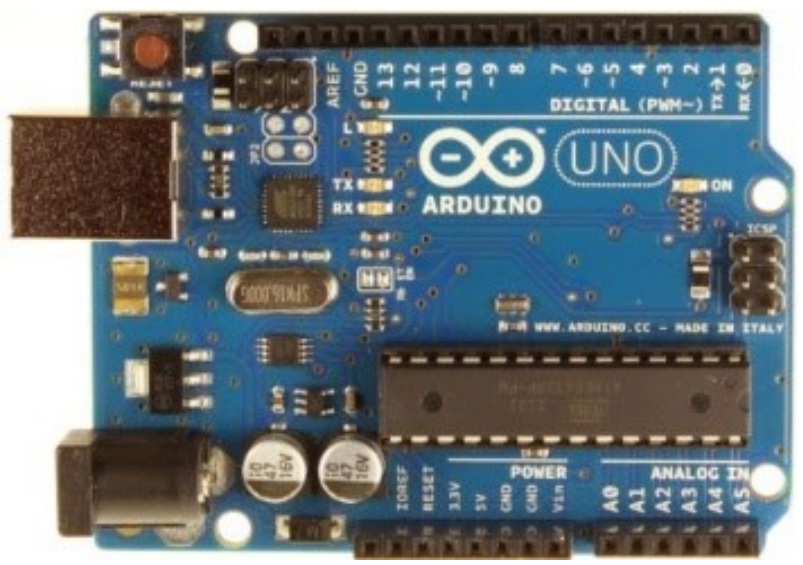

Figure 10. Arduino UNO R3

\subsection{Microcontroller Selection}

From the servo motor specifications needed to drive the handgrip, the microcontroller that can be used is the Arduino UNO R3, as shown in Figure 10, with the specifications described in Table 7 .

\subsection{Material Strength Analysis}

With the FFA force and FH force that occur, a stress simulation of Aluminum 6061 material is carried out, the maximum yield strength stress that occurs is $3.908 \mathrm{MPa}$. Because the object is dynamic and has a shock load, the safety factor or $\mathrm{N}$ is 3 . The yield strength of the material is obtained from Equation 5 .

Figure 11 only has blue color because the software analysis process on mass reading is not optimal. However, in manual calculations, with this yield strength, this device is able to operate.

$\begin{aligned} \text { Yield Strength Material Syp } & >(\mathrm{N} . \text { Smax }) / 0.555 \\ \text { Syp } & >(3 .(3.908)) / 0.555 \\ \text { Syp } & >21.12 \mathrm{MPa} \\ \text { Syp } & >3063.197 \mathrm{psi}\end{aligned}$
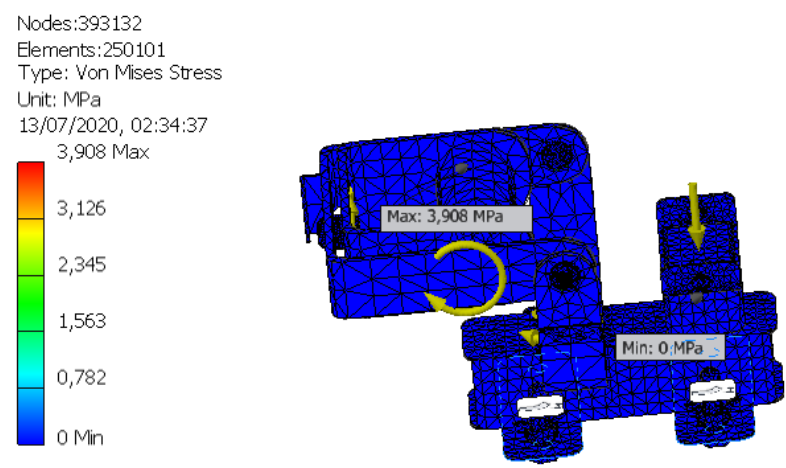

Figure 11. Analysis of stress occurring on the wrist rehabilitation device 
Table 7. Specifications Arduino UNO R3

\begin{tabular}{ll}
\hline \multicolumn{1}{c}{ Parameter } & \multicolumn{1}{c}{ Specification } \\
\hline Microcontroller & $:$ ATmega328P \\
Operating Voltage & $: 5 \mathrm{~V}$ \\
Input Voltage (recommended) & $: 7-12 \mathrm{~V}$ \\
Input Voltage (limit) & $: 6-20 \mathrm{~V}$ \\
Digital I/O Pins & $: 14$ (of which 6 provide PWM output) \\
PWM Digital I/O Pins & $: 6$ \\
Analog Input Pins & $: 6$ \\
DC Current per I/O Pin & $: 20 \mathrm{~mA}$ \\
DC Current for 3.3V Pin & $: 50 \mathrm{~mA}$ \\
Flash Memory & $: 32 \mathrm{~KB}$ (ATmega328P) of which 0.5 KB used by bootloader \\
SRAM & $: 2 \mathrm{~KB}$ (ATmega328P) \\
EEPROM & $: 1 \mathrm{~KB}$ (ATmega328P) \\
Clock Speed & $: 16 \mathrm{MHz}$ \\
Length & $: 68.6 \mathrm{~mm}$ \\
Width & $: 53.4 \mathrm{~mm}$ \\
Weight & $: 25 \mathrm{~g}$ \\
\hline
\end{tabular}

Table 8. Manufacturing process for base frame and locking bracket

\begin{tabular}{lclll}
\hline Main Components & Amount & Dimensions & Process & \multicolumn{1}{c}{ Machine } \\
\hline Base Frame & 1 & $\begin{array}{l}\mathrm{H} 60 \times 60 \mathrm{~mm}, \\
\mathrm{~T}=2 \mathrm{~mm}\end{array}$ & $\begin{array}{l}\text { Cutting } \\
\text { Grinding } \\
\text { Drilling }\end{array}$ & $\begin{array}{l}\text { Circular Saw } \\
\text { Grinding Machine } \\
\text { Drilling Machine }\end{array}$ \\
\hline Locking Bracket & 2 & $\begin{array}{l}150 \times 50 \mathrm{~mm}, \\
\mathrm{~T}=2 \mathrm{~mm}\end{array}$ & $\begin{array}{l}\text { Cutting } \\
\text { Grinding }\end{array}$ & $\begin{array}{l}\text { Circular Saw } \\
\text { Grinding Machine }\end{array}$ \\
\hline
\end{tabular}

\subsection{Manufacturing Process Planing}

In order to make a lightweight device, except for pin, nut, and bolts, almost all of the main components are made of aluminum alloy. The machining process that will be carried out to make wrist rehabilitation equipment includes bending, cutting, milling, turning, drilling and welding. Here will be shown only an example of the manufacturing process of base frame and locking bracket, as shown in Table 8 .

\subsection{Assembly Flow Chart}

After analyzing the manufacturing process, the assembly process is then carried out. The assembly process includes all the components of the wrist rehabilitation equipment from the body frame, bolts, nuts, pins, Arduino, and servo motors. The assembly process begins with a body frame which consists of several sub-components, namely the Base Frame, Forearm Plate, Hand Plate-A, Hand Plate-B, and Hand Plate-C.

To assemble the base frame and the forearm plate, welding is done between the hollow aluminum from the base frame and the hollow aluminum from the forearm plate. The next step is to connect the base frame to hand plate-A by attaching a pin to each hole. Next, connect hand plate-A with hand plate-B with pins in the holes on the right and left sides. Next, attach hand plate-B to hand plate- $C$ with pins at the end of each plate. The final assembly process is to install the nuts and bolts in each hole on the locking bracket. The diagram of the wrist strap rehabilitation equipment assembly process with the help of a servo motor can be seen in Figure 12 .

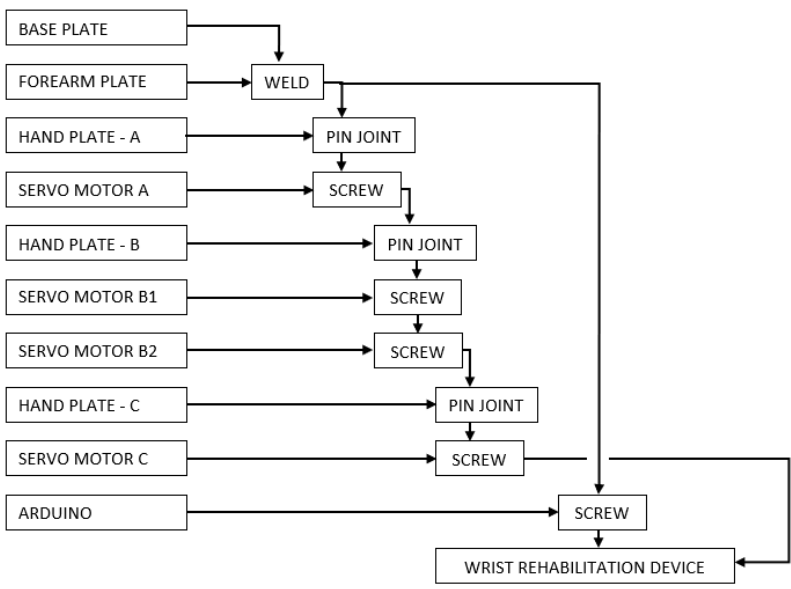

Figure 12. Flowchart of wrist rehabilitation equipment 


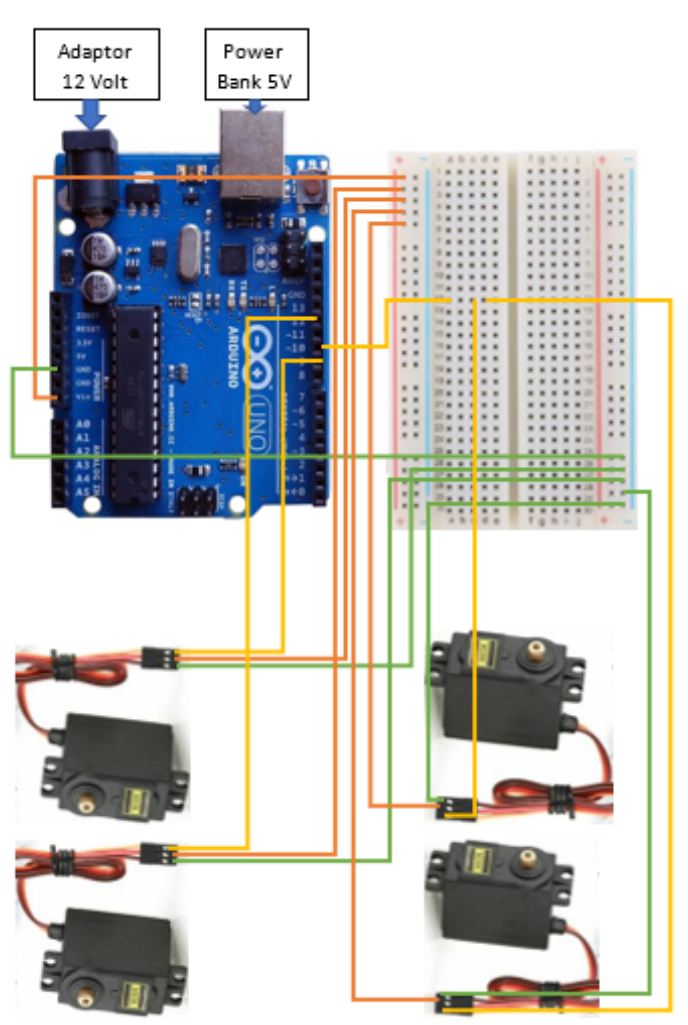

Figure 13. Arduino circuit and servo motor

The Arduino circuit and the servo motor can be seen in Figure 13. Assembly starts from installing 1 servo SG90, 1 servo DS3225 and 2 servo 1501 MG on each of the available pins. After that, connect the jumper cables from each servo to the Arduino. The positive jumper (orange line) is connected to Vin, the negative jumper (green line) is connected to GND (Ground), and the drive jumper (yellow line) is connected to the digital socket.

\section{Conclusion}

From the design of the rehabilitation equipment that has been carried out, it has the specifications of 350.459 $\mathrm{mm}$ long, $216 \mathrm{~mm}$ wide, $167.632 \mathrm{~mm}$ high, and weight $5.624 \mathrm{~kg}$. The RULA value obtained in the position of the hand holding the grip by looking up (pronation) and the position of the hand holding it (supination) is 3 . This means that the design of the Post-Stroke Patient Wrist Rehabilitation Equipment is still comfortable to use. With a mass of $100 \mathrm{~kg}$, the stress that occurs at the most critical part - the handle is 3063.197 psi, while the allowable stress of Aluminum 6061 is 8000 psi, so it is a safe material to use. The machining process that is planned for making wrist rehabilitation equipment mostly includes the bending, drilling and milling processes. To drive the servo motor and get the training torque to move the wrist movements flexibly / extension, abduction/adduction, and pronation/supination, the Arduino IDE program (UNO Program) can be adjusted (adjustable), adjusting the wrist strap strength of each patient.

\section{References}

[1] K. H. Kroemer, H. B. Kroemer, and K. E. KroemerElbert, Ergonomics: how to design for ease and efficiency. Pearson College Division, 2001.

[2] K. T. Ulrich, Product design and development. Tata McGraw-Hill Education, 2003.

[3] I. M. L. Batan, . Desain Produk, Edisi Pertama. Surabaya: Guna Widya, 2021.

[4] A. Freivalds, Biomechanics of The Upper Limbs - Mechanics, Modeling, and Musculoskeletal Injuries. London, New York and Washington DC: CRC Press, 2004.

[5] L. McAtamney and E. N. Corlett, "Rula: a survey method for the investigation of work-related upper limb disorders," Applied ergonomics, vol. 24, no. 2, pp. 91-99, 1993.

[6] F. W. Smith, Materials Science and Engineering an Introduction. United State of America: John Wiley \& Sons, Inc, 1994.

[7] W. Prok, J. Gessal, and L. Angliadi, "Pengaruh latihan gerak aktif menggenggam bola pada pasien stroke diukur dengan handgrip dynamometer," eCliniC, vol. 4, no. 1, 2016. 